\title{
LA RENUNCIA A OBJETAR,LAS NOTIFICACIONES Y LOS PLAZOS EN EL ARBITRAJE
}

\author{
Mario Castillo Freyre \\ Rita Sabroso Minaya \\ Laura Castro Zapata \\ Jhoel Chipana Catalán $n^{4}$
}

\section{RESUMEN}

A través del presente ensayo, los autores comentan el tratamiento de la renuncia a objetar, así como lo relativo a las notificaciones y los plazos en el arbitraje. Estas materias se encuentran reguladas en el Decreto Legislativo N. ${ }^{\circ} 1071$ (en adelante, la Ley de Arbitraje), a través de sus artículos 11 y 12 . El análisis realizado no solo importa el estudio de los alcances y limitaciones de ambas materias, sino también algunas críticas a las mismas sobre temas que se encuentran relacionados a ellas.

\section{ABSTRACT}

In this paper, the authors discuss the treatment of the issue of the waiver to the right to object, the terms of services, and procedural timetable in arbitration proceeding. These matters are governed by Legislative Decree 1071 (hereinafter, the Arbitration Act), through Articles 11 and 12. This analysis not only studies the scope and limitations of these subjects, but also some criticism to them about related issues.

\section{PALABRAS CLAVE}

Arbitraje, renuncia, objetar, plazos, notificaciones.

\section{KEYWORDS}

Arbitration, waiver, right to object, procedural timeline, terms of service.

1 Mario Castillo Freyre, Magíster y Doctor en Derecho, Abogado en ejercicio, socio del Estudio que lleva su nombre; profesor principal en la Pontificia Universidad Católica del Perú. Miembro de Número de la Academia Peruana de Derecho. Director de las colecciones Biblioteca de Arbitraje y Biblioteca de Derecho de su Estudio. www.castillofreyre.com.

2 Rita Sabroso Minaya, Abogada del Estudio Mario Castillo Freyre. Profesora de Arbitrajes Especiales en la Facultad de Derecho de la Universidad de Lima. Con estudios en la Maestría de Derecho de la Competencia y Propiedad Intelectual en la Pontificia Universidad Católica del Perú.

3 Laura Castro Zapata, Abogada por la Universidad Femenina del Sagrado Corazón. Magíster en Derecho, con mención en Derecho Empresarial, por la Universidad de Lima. Ha concluido sus estudios en el Doctorado en Derecho de la Pontificia Universidad Católica del Perú. Dirige el área corporativa del Estudio Mario Castillo Freyre y también se desempeña como Árbitro.

4 Jhoel Chipana Catalán, Abogado por la Pontificia Universidad Católica del Perú, Profesor de Derecho Civil en la Universidad de San Martín de Porres, Abogado en el Estudio Mario Castillo Freyre y Secretario Arbitral en procesos Ad-Hoc. 


\section{LA RENUNCIA A OBJETAR}

El tema de la renuncia a objetar se encuentra regulado en el artículo 11 de la Ley de Arbitraje, ${ }^{5}$ que establece lo siguiente:

\section{Artículo 11.- Renuncia a ob- jetar \\ Si una parte que conocien- do, o debiendo conocer, que no se ha observado o se ha infringido una norma de este Decreto Legislativo de la que las partes pueden apartarse, o un acuerdo de las partes, o una disposi- ción del reglamento arbi- tral aplicable, prosigue con el arbitraje y no objeta su incumplimiento tan pron- to como le sea posible, se considerará que renuncia a objetar el laudo por dichas circunstancias.}

El contenido de esta norma es muy importante, en la medida de que no se trata en el proceso arbitral de sembrar vicios para luego cosechar nulidades.

Guilarte Gutiérrez ${ }^{6}$ señala que, en definitiva, supone una fórmula de poner coto a la eventualmente abusiva utilización del recurso de anulación mediante la alegación de deficiencias que en su momen- to no fueron tempestivamente denunciadas, pero en las que se intenta fundar la claudicación del pronunciamiento arbitral.

De esta manera, se dota de claridad a un silencio derivado de quien pudiendo hacerlo no efectúa la oportuna denuncia de la infracción cometida, que sólo intenta hacer valer cuando el laudo le resulta adverso. ${ }^{7}$

En efecto, si se presenta un vicio, éste tiene que ser denunciado inmediatamente en el acto procesal siguiente. Es decir, por ejemplo, si el tribunal arbitral infringiera alguna disposición en el debido proceso a través de una resolución, inmediatamente deberá interponerse el recurso de reconsideración respectivo.

Si este recurso es declarado infundado, pues ahí se tendrá luego seguramente una causal - si calza dentro de las señaladas por la Ley- para poder anular el laudo. De lo contrario, se considera que la parte ha renunciado a objetar, es decir, que ha convalidado los eventuales vicios del proceso.

Debemos considerar que la protesta tiene como finalidad-precisamente- que el árbitro pueda rectificar y subsanar la infracción.

Asimismo, la renuncia se produce cuando - aun sin que se haya establecido necesariamente un plazo- se omite toda protesta ante la eventual y conocida infracción.

No hay renuncia, en cambio, cuando la resolución que pone fin al incidente no es susceptible de recurso alguno y la parte que es vencida en el incidente nada dice. $Y$ es que, precisamente, nada dice porque nada se puede decir, al ser irrecurrible dicha resolución.

\subsection{LA TEORÍA DE LOS ACTOS PROPIOS Y LA RENUNCIA AL DERECHO A OBJETAR}

Mantilla-Serrano ${ }^{8}$ afirma que esta norma no sólo en nada vulnera el derecho de defensa, sino que lo fortalece, protegiendo a una parte de la actitud reticente de otra que tan sólo, una vez conocido el resultado del arbitraje, aduciría tardíamente, cuando ya nada puede hacerse para remediarla, una alegada violación que podría permitirle escapar a los efectos de un laudo desfavorable. Se trata de una mera expresión de los principios de

5 El artículo 11 de la Ley de Arbitraje encuentra su antecedente en el artículo 4 de la Ley Modelo Uncitral y en el artículo 95 de la derogada Ley General de Arbitraje; preceptos que establecen lo siguiente:

Artículo 4.- Renuncia al derecho a objetar

Se considerará que la parte que prosiga el arbitraje conociendo que no se ha cumplido alguna disposición de la presente Ley de la que las partes puedan apartarse o algún requisito del acuerdo de arbitraje y no exprese su objeción a tal incumplimiento sin demora injustificada o, si se prevé un plazo para hacerlo, dentro de ese plazo, ha renunciado a su derecho a objetar.

Artículo 95. - Renuncia al derecho a objetar

Se considerará que renuncia a su derecho a objetar el arbitraje la parte que lo prosiga conociendo que no se han (sic) cumplido alguna disposición de la presente Sección de las que las partes puedan apartarse, o algún requisito del convenio arbitral, y no exprese su objeción a tal incumplimiento sin demora injustificada o dentro de un plazo pactado.

6 GUILARTE GUTIÉRREZ, Vicente. «Renuncia tácita a las facultades de impugnación». En: Comentarios prácticos a la Ley de Arbitraje. Valladolid: Editorial Lex Nova, 2004, p. 126.

7 Ídem, p. 132.

8 MANTILLA-SerRano, Fernando. Ley de Arbitraje. Una perspectiva internacional. Madrid: lustel, 2005, pp. 69 y 70. 
buena fe y de la prohibición de venire contra factum proprium.

En efecto, incluso la Exposición de Motivos de nuestra Ley de Arbitraje señala que este artículo pretende garantizar la buena fe con la que deben participar las partes en un arbitraje, evitando que se amparen conductas que entran en contradicción con los actos propios de quien pretende objetar las actuaciones arbitrales.

Para Borda, ${ }^{9}$ la Teoría de los Actos Propios constituye una regla derivada del principio general de la buena fe, que sanciona como inadmisible toda pretensión lícita pero objetivamente contradictoria con respecto al propio comportamiento anterior efectuado por el mismo sujeto.

Al respecto, Puig Brutau ${ }^{10}$ señala que la base de la doctrina está en el hecho de que se ha observado una conducta que justifica la conclusión o creencia de que no se hará valer un derecho. Se supone, pues, cierta conducta que induce razonablemente a la creencia de que el derecho no existe o no se hará efectivo.

Por su parte, Compagnucci de Caso $^{11}$ afirma que la doctrina de los actos propios importa una barrera opuesta a la pretensión judicial, impidiéndose con ello el obrar incoherente que lesiona la confianza suscitada en la otra parte de la relación e impone a los sujetos un comportamiento probo en las relaciones jurídicas, agregando que no es posible permitir que se asuman pautas que susciten expectativas o confianza en un desarrollo ulterior y luego se contradiga al efectuar un reclamo judicial.

Fueyo $^{12}$ también nos da una definición que él llama explicativa, al señalar que la doctrina de los actos propios es un principio general de Derecho, fundado en la buena fe, que impone un deber jurídico de respeto y sometimiento a una situación jurídica creada anteriormente por la conducta del mismo sujeto.
Como presupuestos de la Teoría de los Actos Propios, la doctrina $^{13}$ destaca fundamentalmente tres:

(a) Una conducta vinculante;

(b) Una pretensión contradictoria; $y$

(c) Identidad de sujetos.

En relación a la conducta vinculante, Betti ${ }^{14}$ nos dice que, en general, puede hablarse de conducta cuando lo que el ordenamiento jurídico valora es, no el acto en sí mismo considerado, sino el acto o la serie de actos, en cuanto son reveladores de un modo general de proceder o de comportarse, es decir, en cuanto revelan una determinada actitud o una determinada toma de posición de la persona respecto a algunos intereses vitales.

Por su parte, Borda ${ }^{15}$ señala que la conducta importa una toma de posición frente a una situación determinada, refleja una actitud. Pero no hablamos de conducta a secas, sino decimos conducta vinculante.

9 Borda, Alejandro.La teoría de los actos propios. Buenos Aires: Abeledo-Perrot, 2000, pp. 51-53.

10 PUIg BrutaU, José. «La Doctrina de los Actos Propios». En Estudio de Derecho Comparado. Barcelona: Ariel, 1951, pp. 101-102.

11 COMPAGNUCCI DE CASO, Rubén. «La doctrina de los propios actos y la declaración tácita de la voluntad». En La Ley: Revista Jurídica Argentina. Buenos Aires: 1985, tomo A, p. 1001.

12 Citado por RIVAS GUZMÁN, Ramón. «La doctrina de los actos propios y el reglamento interno de la empresa». En Contratos. Santiago de Chile: Editorial Jurídica de Chile, 1991, p. 192.

13 Comparten esta clasificación: Borda, Alejandro. Op. cit., pp. 65-87; EKDAHL EsCoBAR, María Fernanda. La doctrina de los Actos Propios. Santiago: Editorial Jurídica de Chile, 1989, pp. 105-118; PeTRONE, Aldo. «La doctrina de los propios actos». En La Ley. Revista Jurídica argentina. Buenos Aires: La Ley, tomo D, 1995, pp. 603-606; FERNÁNDEZ FERNÁNDEZ, César. «La doctrina de los actos propios y su aplicación en la legislación peruana». En Revista Jurídica del Perú. Trujillo: Normas Legales, n. ${ }^{\circ}$ 58, pp. 197-205; LóPEZ MESA, Marcelo y Carlos RogEL VIDE. La doctrina de los Actos Propios. Doctrina y jurisprudencia. Montevideo - Buenos Aires: Editorial Reus y Editorial IB de F, 2005, p. 110.

Sin embargo, en relación al segundo presupuesto, cierta parte de la doctrina distingue, por un lado, el ejercicio de la facultad o del derecho (pretensión) y, por otro, la contradicción. Se encuentran en esta línea de pensamiento: Díez-PICAZo PonCE DE León, Luis. La doctrina de los Actos Propios. Barcelona: Bosch, 1962, pp. 194-232, MOISSET DE ESPANÉS, Luis. «Teoría de los actos propios y renuncia tácita». En La Ley: Revista Jurídica Argentina. Buenos Aires: 1983, tomo D, pp. 523-527; Arana GARcía, Estanislao. Op. cit., pp. 31-42; EYZAGUIRRE B., José María. Breve estudio sobre la teoría comparada del propio acto. Santiago de Chile: Universidad de Chile, 1985; Rivas GuzMán, Ramón. Op cit., pp. 191-207;CompagnuCCI DE CASO, Rubén. Op. cit., pp. 1000-1007.

14 Citado por Díez-PICAZo PonCE DE León, Luis. Op. cit., p. 195.

15 BORDA, Alejandro. Op. cit., p. 68. 
Al respecto, Petrone ${ }^{16}$ sostiene que la conducta vinculante consiste en un acto o serie de actos que revelen una determinada actitud o decisión de una persona respecto de intereses vitales que se expresan, o más concretamente, «un acto volitivo, exteriorizado de la persona sobre un interés trascendente».

Por otro lado, debemos precisar que en este primer presupuesto, el de conducta vinculante, podemos distinguir cuatro elementos: (i) debe ser relevante para el Derecho; (ii) debe ser válida y eficaz; (iii) debe presentarse en una misma situación jurídica; y (iv) debe ser anterior (tener una apreciable distancia temporal) a la conducta contradictoria. ${ }^{17}$

Como segundo presupuesto de la Teoría de los Actos Propios se señala el ejercicio de una facultad o de un derecho subjetivo, por la misma persona que crea la situación litigiosa debido a la contradicción atentatoria de la buena feexistente entre ambas conductas.

Para aplicar la Teoría de los Actos Propios se requiere la existencia de una pretensión contradictoria, expresión que encierra diversos matices, según Borda. ${ }^{18}$ Por un lado, es la emisión de una nueva conducta o un nuevo acto; por otro lado, esta conducta o acto importa ejercer una pretensión.
Esta pretensión, que en otro contexto es lícita, resulta inadmisible por ser contradictoria de la primera conducta.

Dentro de tal orden de ideas, debemos tener presente que la conducta o acto posterior -considerado aisladamenteno tiene mayor sentido. Lo relevante de esta conducta posterior es que significa ejercer una pretensión contradictoria respecto de la conducta vinculante.

De este modo, la pretensión contradictoria constituye -de por si- el ejercicio de un derecho subjetivo, y-como tallícito y merecedor de tutela.

Por otra parte, como tercer presupuesto de la Teoría de los Actos Propios, tenemos a la identidad de sujetos que se vinculan en ambas conductas.

La conducta contradictoria emplazada en una persona requiere ineludiblemente su comparación con otra conducta precedente, efectuada por la misma persona o por personas distintas con una misma representación. Ello importa que la identidad a la que nos referimos puede ser tanto física como jurídica.

A entender de Mairal, ${ }^{19}$ este tercer presupuesto se refiere a que exista una conducta previa y una pretensión posterior emanada de la misma persona (concepto que incluye a sus representantes o sucesores) y que se hayan producido ambas frente a la misma contraparte y dentro del marco de la misma relación o situación jurídica. Es decir, que exista identidad de partes y unidad de situación jurídica.

En consecuencia, podemos afirmar que la Teoría de los Actos Propios es una limitación al ejercicio de los derechos subjetivos, impuesta por el deber de un comportamiento coherente con la conducta anterior del sujeto que suscita en otro una fundada confianza.

Asimismo, vemos que lo primero es el conocimiento por parte del perjudicado por la infracción de la existencia de ésta, la misma que ha de consistir en la vulneración de alguna regla establecida en la ley o que resulte de lo acordado por las partes en el convenio arbitral.

Luego, el perjudicado omite objetar, con lo que convalida la infracción.

$Y$, finalmente, el perjudicado pretende objetar las actuaciones arbitrales, cuando -en la mayoría de los casos- el laudo no le es favorable.

Al respecto, Mantilla-Serrano ${ }^{20}$ señala que no puede haber trasgresión cuando las partes, con conocimiento de la conducta contraria a lo estipulado o a lo dispuesto, no han manifesta-

16 Petrone, Aldo. «La doctrina de los propios actos». En La Ley. Revista Jurídica argentina. Buenos Aires: La Ley, tomo D, 1995, p. 604.

17 Sobre cada uno de estos presupuestos, recomendamos ver: CASTILLO FrEYRE, Mario y Rita SABROSO MINAYA. La teoría de los actos propios. Lima: Palestra editores S.A.C., 2006, pp. 81 y ss.

18 Borda, Alejandro. Op. cit., p. 75.

19 MAIRAL, Héctor A. La doctrina de los propios actos y la administración pública. Buenos Aires: Ediciones Depalma, 1988, p. 6.

20 Mantilla-Serrano, Fernando. Op. cit., p. 69. 
do objeción a esa conducta de manera tempestiva. Se entiende que, al consentir la posible trasgresión, las partes la han convalidado y con su conducta han derogado la disposición legal o el convenio arbitral, lo cual les está totalmente permitido gracias a la naturaleza consensual del arbitraje y al sumo respeto a la autonomía de las partes, amparadas por la Ley de Arbitraje.

En consecuencia, el artículo 11 de la Ley de Arbitraje exige coherencia en el obrar del sujeto y sanciona la conducta contradictoria.

\section{NOTIFICACIONES Y PLAZOS}

Estos temas se encuentran regulados en el artículo 12 de la Ley de Arbitraje ${ }^{21}$ :

\section{Artículo 12.- Notificaciones y plazos}

Salvo acuerdo en contrario de las partes, se aplicarán las disposiciones siguientes:

a. Toda notificación o comunicación se considerará recibida el día en que haya sido entregada personalmente al destinatario o en que haya sido entregada en el domicilio señalado en el contrato o, en su defecto, en el domicilio o residencia habitual o lugar de actividades principales. Si no pudiera determinarse, tras una indagación razonable, ninguno de esos lugares, se considerará recibida el día en que haya sido entregada o intentada su entrega, por correo certificado o cualquier otro medio que deje constancia, en el último domicilio o residencia habitual - lugar de actividades principales conocidos del destinatario. b. Asimismo, será válida la notificación o comunicación realizada por fax u otro medio de telecomunicación electrónico, telemático o de otra clase semejante que permitan el envío y la recepción de escritos y documentos, dejando constancia de su remisión y recepción y que hayan sido designados por la parte interesada.

c. Los plazos establecidos en este Decreto Legislativo se computarán desde el día siguiente al de recepción de la notificación o comunicación. Si el último día del plazo fuere inhábil en el lugar de recepción de la notificación o comunicación, se extenderá hasta el primer día laborable siguiente. Los plazos establecidos por días se computarán por días hábiles.

21 El artículo 12 de la Ley de Arbitraje tiene su antecedente en el artículo 3 de la Ley Modelo Uncitral: Artículo 3.- Recepción de comunicaciones escritas

1) Salvo acuerdo en contrario de las partes:

a) se considerará recibida toda comunicación escrita que haya sido entregada personalmente al destinatario o que haya sido entregada en su establecimiento, residencia habitual o domicilio postal; en el supuesto de que no se descubra, tras una indagación razonable, ninguno de esos lugares, se considerará recibida toda comunicación escrita que haya sido enviada al último establecimiento, residencia habitual o domicilio postal conocido del destinatario por carta certificada o cualquier otro medio que deje constancia del intento de entrega; b) la comunicación se considerará recibida el día en que se haya realizado tal entrega.

2) Las disposiciones de este artículo no se aplican a las comunicaciones habidas en un procedimiento ante un tribunal.

Asimismo, cabe anotar que dicho artículo posee su antecedente en los artículos 7 y 8 de la derogada Ley General de Arbitraje, Ley $n .^{\circ} 26572$; preceptos que establecen lo siguiente:

Artículo 7. - Plazos

Salvo acuerdo en contrario de las partes, los plazos se computan por días hábiles, salvo que expresamente se señale que son días calendario. Son inhábiles los días domingo, sábado y feriados no laborables, así como los días de duelo nacional no laborable declarados por el Poder Ejecutivo. Excepcionalmente, los árbitros podrán habilitar, previa notificación a las partes, días inhábiles para la actuación de determinadas actuaciones.

Artículo 8. - Recepción de comunicaciones escritas

Salvo acuerdo en contrario de las partes, se considerará recibida toda comunicación que haya sido entregada al destinatario o que lo haya sido en el domicilio señalado en el contrato. De no haberse señalado uno, la entrega podrá hacerse en su domicilio real o residencia habitual. En el supuesto de que no pudiera determinarse ninguno de esos lugares, tras una indagación razonable, se considerará recibida toda notificación que haya sido enviada al último domicilio real o residencia habitual conocido del destinatario por carta certificada o cualquier otro medio que deje constancia fehaciente de la entrega.

Serán válidas las notificaciones por cable, télex, facsímil o medios similares que inequívocamente dejen constancia de la comunicación, salvo que lo contrario estuviera previsto en el convenio arbitral o en el reglamento de la institución arbitral.

Toda comunicación se considerará recibida el día en que se haya realizado su entrega. 
Se consideran inhábiles los días sábados, domingos y feriados así como los días no laborables declarados oficialmente.

Teniendo en cuenta el texto del citado artículo, vamos a analizar por separado el tema de las notificaciones y el de los plazos.

\subsection{NOTIFICACIONES}

En primer término, debemos resaltar el carácter supletorio de lo establecido por el artículo 12 de la Ley de Arbitraje. En efecto, dicha norma es de aplicación supletoria en caso las partes no hayan establecido algo en relación a las notificaciones y plazos, o cuando habiéndose pactado sobre el particular, existan vacíos.

En efecto, como bien señala Mantilla-Serrano, ${ }^{22}$ nuevamente impera el principio de la autonomía de la voluntad privada. Las partes pueden libremente acordar todo lo relacionado con las circunstancias de modo, tiempo y lugar de las notificaciones y comunicaciones, así como de los plazos en el arbitraje.

Al respecto, Toribios Fuentes ${ }^{23}$ señala que el acuerdo de las partes sobre estos temas, puede efectuarse de diversas formas:

a) Ad-hoc: cuando las partes, en el propio convenio arbitral, determinan las normas de procedimiento y, en consecuencia, establecen con- cretas previsiones respecto del cómputo de los plazos procedimentales, notificaciones y comunicaciones.

b) Institucional: cuando las partes encomiendan la administración del arbitraje a un centro, el cual ejercerá su función conforme a sus propios reglamentos, los que contendrán normas respecto de las comunicaciones, notificaciones y cómputo de los plazos.

c) Reglamentario: las partes pueden someterse al reglamento de una institución, pero sin encomendarle la administración del arbitraje, en cuyo caso ese concreto reglamento también integrará la voluntad de las partes.

Asimismo, el citado autor no encuentra inconveniente en que las partes, en atención al principio de autonomía de la voluntad que rige en las actuaciones arbitrales, puedan modificar durante la tramitación del procedimiento el concreto régimen de comunicaciones, notificaciones y plazos al que se hayan sometido, sustituyéndolo -total o parcialmente- por otro distinto.

Por otro lado, cabe precisar que el artículo 12 de la Ley establece las reglas sobre notificaciones y plazos que se aplican tanto a las actuaciones dirigidas a iniciar el arbitraje como a las actuaciones del proceso arbitral en sí mismo.
Otro aspecto a tener presente, según Yáñez Velasco, ${ }^{24}$ es que la disyuntiva utilizada entre los términos «notificación» y «comunicación» plantea la duda de si significan lo mismo o de si son dos posibilidades distintas pero que observan idéntico tratamiento. La primera de las opciones sería absurda pero redundante, acaso fruto de una mala técnica legislativa. Pero la segunda de las alternativas exige definir qué es «notificación»y qué es "comunicación», y no parece posible encontrar una distinción convincente. La comunicación o los actos de comunicación conllevan una noción genérica que engloba la notificación como un acto de comunicar y es, en ese sentido, en el que la notificación tiene un contenido procesal específico.

Ahora bien, el literal a) del artículo 12 inicia su regulación, señalando que «Toda notificación o comunicación se considerará recibida el día en que haya sido entregada personalmente al destinatario».

Esta primera disposición, relativa a la entrega personal al destinatario, se basa en la posibilidad de que se le notifique, por ejemplo, al destinatario directamente en una audiencia o que el destinatario se apersone al Centro de Arbitraje o a la sede del tribunal arbitral y que allí se le pueda notificar circunstancialmente la resolución.

A entender de Toribios, ${ }^{25}$ lo ideal sería que todas y cada

\footnotetext{
22 Mantilla-Serrano, Fernando. Op. cit., p. 64.

23 TORIBIOS FUENTES, Fernando. «Notificaciones, comunicaciones y cómputo de plazos». En Comentarios prácticos a la Ley de Arbitraje. Valladolid: Editorial Lex Nova, 2004, pp. 108-109.

24 Yáñez Velasco, Ricardo. Comentarios a la nueva Ley de Arbitraje. Valencia: Tirant lo Blanch, 2004, p. 241.

25 Toribios Fuentes, Fernando. Op. cit., p. 112.
} 
una de las resoluciones arbitrales se comunicasen directa y personalmente a su destinatario, bien en su propia persona o en la de un representante; sin embargo, en la práctica, sabida es la dificultad de llevarlo a cabo. Por ello, tradicionalmente se ha admitido la práctica de los actos de comunicación en receptores subsidiarios que en atención a especiales situaciones de proximidad con el destinatario, garantizan con un alto grado de probabilidad la recepción por éste. Es decir, que sea entregado a persona distinta del destinatario, pero siempre y cuando la entrega se produzca en alguno de los lugares previstos por la norma.

De esta manera, el referido literal a) del artículo 12 también establece que toda notificación o comunicación se considerará recibida el día en que «haya sido entregada en el domicilio señalado en el contrato».

En realidad ésta es la regla usual, ya que el domicilio contractual es aquél que las partes han establecido en el contrato y en él se entenderán recibidas todas las comunicaciones judiciales, arbitrales o extrajudiciales o extra-arbitrales, según sea el caso.

Asimismo, el literal a) establece que, en defecto del domicilio contractual, la notificación se considerará recibida en el domicilio o residencia habitual o lugar de actividades principales.

En ese sentido, habría que analizar si esta norma era necesaria o no. Decimos esto porque, para empezar, el domicilio contractual es aquél que las partes deben mantener a lo largo de la relación contractual. Y si se produjera un cambio de domicilio, pues, el mismo se deberá comunicar a la contraparte, en consideración a lo dispuesto por los artículos 39 y 40 del Código Civil. ${ }^{26}$

Como bien señala Torres Carrasco, ${ }^{27}$ habiendo declarado el Código Civil -en su artículo 33- su adhesión a la teoría objetiva de la constitución del domicilio, por la cual basta el simple hecho de residir en un lugar para considerar a la persona domiciliada en éste, resulta completamente lógico que la variación del domicilio se verifique también por el simple hecho de que la persona traslade su residencia a un nuevo lugar.

Ese sentido, entendemos que sobre las partes pesa no sólo el deber de veracidad, al facilitar los datos correctos de su domicilio, lugar de residencia, etc., para su ulterior notificación, sino igualmente el de comunicar a la contraparte (antes del inicio del arbitraje) o al tribunal arbitral (luego de instalado el arbitraje) cualquier variación del domicilio que pueda producirse.

Dentro de tal orden de ideas, consideramos innecesaria cualquier otra referencia distinta al domicilio contractual.

A nuestro entender, para una correcta comunicación o notificación bastará con que se notifique en el domicilio contractual (el originalmente establecido o el modificado, siempre y cuando dicha modificación haya sido puesta en conocimiento de la contraparte) o en el domicilio que se ha consignado en el Acta de Instalación (que podría no ser el contractual).

Decimos esto porque, si se trata de un arbitraje ad-hoc, lo usual es que en la propia Acta de Instalación se establezca que el domicilio no se entenderá modificado, mientras no haya comunicación expresa por escrito presentada ante el tribunal arbitral.

Si se trata de un arbitraje institucional lo común es que el Reglamento del Centro de Arbitraje establezca que el domicilio - para efecto de las notificaciones o comunicaciones- es aquél que las partes han designado expresamente para los fines del arbitraje.

Sin embargo, entendemos que la Ley ha querido cubrir todos

26 Artículo 39.- «El cambio de domicilio se realiza por el traslado de la residencia habitual a otro lugar».

Artículo 40.- «El deudor deberá comunicar al acreedor el cambio de domicilio señalado para el cumplimiento de la prestación obligacional, dentro de los treinta (30) días de ocurrido el hecho, bajo responsabilidad civil y/o penal a que hubiere lugar.

El deudor y los terceros ajenos a la relación obligacional con el acreedor, están facultados para oponer a éste el cambio de su domicilio.

La oponibilidad al cambio de domicilio se efectuará mediante comunicación indubitable».

27 Torres Carrasco, Manuel Alberto. «Cambio de domicilio». En: Código Civil Comentado». Tomo I, Lima: Gaceta Jurídica S.A., 2003, p. 277. 
los posibles supuestos, a efectos de que siempre exista una posibilidad para una correcta comunicación o notificación.

Como señala Yáñez Velasco, ${ }^{28}$ no hacerse localizable puede suponer inconvenientes importantes, principalmente en lo que respecta a los derechos de audiencia, contradicción y defensa, y lo que en su virtud afecta la prosecución natural del arbitraje.

Recordemos que el artículo 12 de la Ley sólo se aplica supletoriamente, es decir, sólo se aplica en caso las partes no hayan pactado algo sobre el particular o cuando el Reglamento al que sometieron el arbitraje tampoco contempla regulación específica sobre el tema de las notificaciones o comunicaciones (supuesto, por lo demás, poco común).

Dentro de tal orden de ideas, cuando el literal a) del artículo 12 de la Ley señala «en defecto", debe entenderse el supuesto en el que no exista domicilio señalado en el contrato. Sólo en ese supuesto se tendría que entregar la notificación o la comunicación en el domicilio habitual o en el lugar de actividades principales.

Pero, reiteramos que si se ha fijado un domicilio contractual, pues será ahí donde se deberá notificar. Aquí no hay opción alguna. Ese domicilio se deberá respetar hasta que se modifique por su titular y ese cambio sea notificado a su contraparte en los términos y alcances del artículo 40 del Código Civil.

Ahora bien, cuando se hace referencia a domicilio o residencia habitual o lugar de actividades principales, se desprende que la ley busca que las notificaciones o comunicaciones sean hechas en cualquier lugar que denote, así no sea de manera permanente, una presencia del destinatario. Bastará así que el interesado demuestre esa presencia del destinatario y conserve prueba de esa entrega, para que la notificación o comunicación se entienda válidamente realizada, siempre y cuando no se pruebe que la parte que hace la notificación sabía o debía haber sabido que la parte notificada no tenía allí su domicilio, residencia habitual, o lugar de actividades. ${ }^{29}$

Agrega el literal a) del artículo 12 de la Ley de Arbitraje, que si no pudiera determinarse - tras una indagación razonable - ninguno de esos lugares, la notificación o comunicación se considerará recibida el día en que haya sido entregada o intentada su entrega por correo certificado o cualquier otro medio que deje constancia en el último domicilio o residencia habitual o lugar de actividades principales conocido del destinatario.

A entender de Mantilla-Serrano, ${ }^{30}$ cuando la mínima presen- cia sea imposible de confirmar «después de una indagación razonable», el criterio de recepción se flexibiliza.

Sobre la «indagación razonable», el citado autor nos dice no puede interpretarse la misma como imponiendo una obligación de investigación; se trata no de probar la diligencia de quien notifica, sino de descartar la situación en que conociendo o debiendo conocer el domicilio, residencial habitual, quien notifica, escoge hacer una notificación en otro sitio. En segundo lugar, esa «indagación razonable» sólo se predica de las partes directamente (no de la institución arbitral, ni del árbitro, ${ }^{31}$ a menos que el reglamento de arbitraje así lo prevea) y sólo se aplicará cuando las partes no hayan regulado, directamente o mediante referencia a un reglamento de arbitraje, lo relativo a las notificaciones.

Por su parte, Toribios ${ }^{32}$ señala que, con buen criterio, se ha pretendido dar solución a los problemas que se plantean cuando, de forma inicial o incluso sobrevenida, se desconoce el lugar en el que se pueda practicar válidamente actos de comunicación con las partes intervinientes en el arbitraje. En realidad, siempre que se desconozca el domicilio, se impone la práctica de la indagación razonable, y ello tanto si se conoce un domicilio y resulta infructuosa la notifi-

YáÑEz Velasco, Ricardo. Op. cit., p. 235.

MANTILLA-SERRANo, Fernando. Op. cit., p. 65.

Ídem, pp. 65 y 66.

31 El árbitro no tiene una obligación independiente de «investigar» por su cuenta el lugar para realizar las notificaciones. El árbitro debe atenerse a lo establecido en el contrato (domicilio contractual) o a lo que la propia parte notificada le informe o, en su defecto, a lo que la otra parte interesada en la notificación le comunique.

32 Toribios Fuentes, Fernando. Op. cit., p. 115. 
cación, como si se produce $a b$ initio ese desconocimiento.

En realidad, a nuestro entender, lo establecido por el literal a) del artículo 12, determina diversos supuestos de aplicación excluyente, a saber:

- En primer lugar, debe dirigirse al domicilio contractual (originalmente pactado o el modificado). Si no hubiere domicilio contractual, se pasará al punto siguiente.

- Si se desconoce un domicilio contractual,la notificación debe dirigirse al domicilio o residencia habitual o al lugar de las actividades principales.

- Si no se puede realizar la entrega en estos lugares, porque no se pueden determinar (a pesar de una indagación razonable), debe entregarse o intentar entregarse por cualquier medio que deje constancia (correo certificado, vía notarial) en el último domicilio o residencia habitual o en el último lugar de las actividades principales.

Sobre el particular, Toribios ${ }^{33}$ señala que ante el fracaso de la indagación, la norma equipara el intento de entrega con la entrega, y tiene por notificado lo que en realidad no se recibió. La Ley de Arbitraje no ha previsto, en ningún momen- to, la comunicación edictal, por lo que el mero intento de notificación, ante el fracaso de la labor indagatoria, hace las veces de pieza de cierre del sistema.

En efecto, como señala Yáñez Velasco, ${ }^{34}$ no parece criticable la supresión de la vía edictal en el procedimiento arbitral, sobre todo si se tiene en cuenta que el arbitraje nace de la voluntariedad de los interesados, por lo que quien necesite ser notificado por edictos (mejor, quien pueda conocer por edictos la comunicación arbitral), difícilmente querrá serlo. ${ }^{35}$

Por otro lado, Toribios ${ }^{36}$ señala que también son un lugar, aunque de naturaleza singular, los que han venido en llamarse medios informáticos o electrónicos. Su especial carácter impide su concreta ubicación en un espacio físico determinado, pues, por todos es sabido, el acceso a una dirección de correo electrónico puede efectuarse en principio, desde cualquier ordenador. Por ese motivo lo calificamos como lugar virtual, pues su existencia no es, propiamente hablando, real.

De esta manera, en el literal b) del artículo 12 de la Ley de Arbitraje, se señala que será válida la notificación o comunicación realizada por fax $\mathrm{u}$ otro medio de telecomunicación electrónico, telemático o de otra clase semejante que permitan el envío y la recepción de escritos y documentos, dejando constancia de su remisión y recepción y que hayan sido designados por la parte interesada.

En realidad, es correcta esta alternativa que brinda el literal b) del artículo 12, en la medida de que faculta a que se utilicen estos medios electrónicos de telecomunicación, a efectos de proceder a las notificaciones.

Al respecto, Mantilla-Serrano ${ }^{37}$ señala que desafortunadamente se ha añadido que la validez de la utilización de estos medios electrónicos está supeditada a que dejen constancia de la remisión y recepción, siempre y cuando hayan sido designados por el interesado, lo cual podría interpretarse como imponiendo condiciones más restrictivas que las previstas cuando se utilicen otros medios de comunicación más tradicionales y podría, por ese solo hecho, desestimular el uso de las nuevas tecnologías, obteniéndose así el resultado contrario al querido por el legislador.

En el Perú, no se recurre con mucha frecuencia a esta forma de notificar, en razón de la poca fiabilidad que se tiene y en función a que todavía se sigue confiando más en los cargos físicos, en los documentos sellados, vale decir, en las notificaciones tradicionales. Generalmente se las utiliza como

TORIBIOS Fuentes, Fernando. Op. cit., p. 116.

34 YÁÑEZ Velasco, Ricardo. Op. cit., p. 236.

35 Ahora bien, otra cosa es que el principio de libertad de procedimiento permita que las partes acuerden la posibilidad de servirse de la vía edictal, o lo hagan los propios árbitros en su defecto, lo que en ningún caso se podría considerar como un recorte de derechos sino precisamente una opción (IBÍDEM).

36 TORIBIOS Fuentes, Fernando. Op. cit., p. 114.

37 Mantilla-Serrano, Fernando. Op. cit., p. 67. 
una notificación complementaria, pero es la notificación física o tradicional la que marca o determina los plazos.

Ahora bien, no coincidimos con Mantilla-Serrano ${ }^{38}$ cuando afirma que debemos entender que la «designación por el interesado» (cuando se trate de quien recibe la notificación), puede hacerse no sólo de manera expresa, sino también implícita, por ejemplo, mediante la utilización habitual en el giro normal de sus negocios o en las comunicaciones con la otra parte de un número de télex o fax o de una dirección de correo electrónico, aun sin que se haya mencionado expresamente que las mismas valen para notificaciones.

A nuestro entender, la designación del medio facsimilar; electrónico o virtual a que se refiere el literal b) del artículo 12 debe ser expresa y de ninguna forma tácita, ya que de lo contrario dicha situación podría llevar a interpretaciones muy subjetivas, que no harían más que perjudicar el correcto y ordenado desarrollo del proceso arbitral. En otras palabras, si la parte no ha establecido expresamente en el proceso o en el contrato un medio de esta naturaleza para que se le notifique, pues no se le podrá notificar a través de este medio, a pesar de que esa dirección virtual sea de conocimiento público. Cualquier notificación ahí realizada será nula.

\subsection{Plazos}

Aquí también debemos resaltar el carácter supletorio de lo establecido por el literal c) del artículo 12 de la Ley de Arbitraje, que regula el tema de los plazos establecidos en dicha Ley. En efecto, las partes tienen plena libertad para regular el tema de plazos; sin embargo, en caso de vacíos, se aplica supletoriamente lo regulado por el referido literal c).

Al respecto, Toribios ${ }^{39}$ precisa que el régimen de plazos -bien sea el pactado o el supletorio- es de aplicación a la totalidad de las actuaciones tendentes a poner en marcha el arbitraje como el conjunto de su tramitación. Sin perjuicio de ello, el régimen de plazos pactado -o el supletorio- no es de aplicación en el seno de los procedimientos que sirven de control o apoyo del arbitraje, los cuales seguirán su propia normativa. Por último, los plazos para iniciar esos procedimientos de apoyo o control del arbitraje, no son considerados de naturaleza procesal por la Ley, por lo que han de someterse necesariamente al régimen de la Ley de Arbitraje para su cómputo.

Ahora bien, en primer lugar, el literal c) del artículo 12 establece que los plazos se computarán desde el día siguiente al de recepción de la notificación o comunicación, lo cual nos parece lógico.
Como bien señala Toribios, ${ }^{40}$ se debe diferenciar, al menos, entre el instante de referencia y el momento inicial del plazo. Al instante de referencia se le denomina dies a quo y puede o no coincidir con el del inicio del plazo.

De esta manera, nuestra Ley de Arbitraje también realiza dicha diferencia. Así el dies a quo (instante de referencia para fijar el momento inicial) es el día en que se notifica la resolución o el laudo, y el momento inicial del cómputo de plazo son las cero horas del día siguiente.

La Ley de Arbitraje mantiene la máxima de que dies a quo non computatur in termino, estableciéndose - de esta manera- un beneficio para el que soporta el plazo, dando - a su vez- mayor fijeza y claridad al cómputo del mismo, al eliminar la posible incertidumbre - dificultad probatoria de la hora exacta de su inicio, contribuyendo así a la seguridad jurídica. ${ }^{41}$

Asimismo, cabe señalar que el referido literal c) contiene una previsión respecto de la eventualidad de que el dies ad quem (momento en el que se produce la finalización del plazo) sea inhábil en el lugar donde se recibe la notificación o comunicación, indicando que en dicho supuesto "se extenderá hasta el primer día laborable siguiente».

\footnotetext{
8 Ibidem.

TORIBIOS FUENTES, Fernando. Op. cit., pp. 116-117.

ÍDEM, pp. 117-118.

Ídem, p. 118.
} 
Sin embargo, la aplicación de este precepto es muy poco usual en el Perú, pues los plazos en el arbitraje no se establecen ni por años ni por meses, sino por días y, en ese caso, el literal c) señala de manera expresa que «los plazos establecidos por días se computarán por días hábiles».

Creemos que ello admite excepción, a saber: que expresamente se señale que son días calendario. Aunque dicha excepción no está contemplada en la Ley, ella se desprende del carácter mismo de supletoriedad que tiene el artículo 12. A diferencia de lo establecido por el artículo 7 de la derogada Ley General de Arbitraje, que sí contemplaba expresamente la posibilidad de que las partes pacten días calendario. No obstante, también resulta inusual que los plazos del arbitraje en el Perú se establezcan en días naturales.

Ahora bien, excepcionalmente, los árbitros podrían habilitar, previa notificación a las partes, días inhábiles para llevar a cabo determinadas actuaciones. No es lo común, pero es una posibilidad que casi siempre se contempla en las Actas de Instalación y que también estaba contemplada por el último párrafo del artículo 7 de la derogada Ley General de Arbitraje, Ley n. 26572.

De igual manera, el literal c) ha considerado inhábiles los sábados, domingos y feriados, así como los días no laborables declarados oficialmente.

Sin embargo, acá subsiste un problema en relación a los mediodías no laborables, tema que surgió a raíz de la declaración de un mediodía no laborable por duelo nacional, a raíz de la muerte del ex Presidente de la República, el doctor Valentín Paniagua Corazao, el 17 de octubre de 2006.

En ese sentido, es recomendable establecer que se computan como días completos no laborables en general, aquéllos no laborables para el sector público, los mediodías festivos o de duelo no laborables.

Finalmente, cabe señalar que el artículo 12 de la Ley de Arbitraje no se pronuncia en torno a la posibilidad de prorrogar los plazos. Este tema se halla regulado en el inciso 4 del artículo 34,el cual establece que el tribunal arbitral podrá, a su criterio, ampliar los plazos que haya establecido para las actuaciones arbitrales, incluso si estos plazos estuvieran vencidos.

Sobre el particular, coincidimos con Toribios, ${ }^{42}$ quien señala que salvo que otra cosa se haya pactado por las partes, los plazos han de ser, como regla general, improrrogables, salvo casos de fuerza mayor apreciados por el tribunal arbitral. En otras palabras, parece razonable entender que no cabe hablar de una improrrogabilidad absoluta (los plazos no se pueden prorrogar en ningún caso), sino relativa (sólo pueden ser prorrogables cuando concurran circunstancias excepcionales).

La improrrogabilidad de los plazos concilia mejor con la naturaleza y finalidad del arbitraje, especialmente si tenemos en cuenta el principio de celeridad, que constituye uno de los motivos por los cuales las partes recurren a este instrumento heterocompositivo. Pero, además, la improrrogabilidad de los plazos supone, con las ventajas inherentes a ello, un fuerte componente de rigor en el procedimiento arbitral. ${ }^{43}$

42 Ídem, p. 124.

43 IBÍDEM. 
